\title{
Surgery for Acute Complicated Tracheal Stenosis
}

\section{Arpad Pereszlenyi}

Department of Thoracic Surgery, Vivantes Clinics Neukölln, Academic Teaching Hospital of Charité University, Berlin, Germany. Email: arpad.pereszlenyi@vivantes.de

Received May $17^{\text {th }}$, 2012; revised June $15^{\text {th }}$, 2012; accepted June $25^{\text {th }}, 2012$

\begin{abstract}
Tracheal stenosis is a serious, life-threatening disease with increasing incidence. Among these stenoses, the number of complicated tracheal lesions, where a resection and anastomosis is not successful or not applicable, is also increasing significantly. These acute situations often need to be managed by a combined surgical technique. The present paper is dedicated to this topic; the management of combined surgical and endoscopic technique in case of complicated long tracheal stenosis.
\end{abstract}

Keywords: Complicated Tracheal Stenosis; Management by a Combined Surgical; Endoscopic Technique

\section{Introduction}

Nowadays, the topic of tracheal stenting is becoming more and more topical, mainly due to the growing problems with acquired postintubation and/or posttracheostomy stenoses [1-3].

The management of an obstructive tracheal lesion, which develops as a result of long-term intubation, is a complex issue that requires an individual approach. A fully developed stenotic lesion with a high degree of obstruction, which is manifested a certain time later after extubation, requires radical surgical resection. As is known, this solution is not always feasible [4,5]. The number of complicated tracheal lesions, where its resection and anastomosis are not successful or not applicable, increases and the situation requires a solution by an endoprosthesis [5-7]. The condition of long, multisegmental tracheal stenosis where the primary reconstructive surgery cannot be performed and the stenting by any kind of endoprosthesis does not present a definitive solution and it can be very challenging even for an experienced tracheal surgeon or interventional bronchologist.

The present paper is dedicated to this topic; the management of complicated long tracheal stenosis by the combination of stenting and surgical techniques.

\section{Case Reports}

The technique of endotracheal stenting together with surgical management is introduced within the following case reports.

\subsection{Case 1}

A 75-year-old female patient with a history of an acute myocardial infarction managed by coronaro-angioplasty and stenting developed acute fibrillations and fluttering postinterventionally. She was immediately reanimated and cardio-versed. Afterwards, within ICU-management, she also underwent a percutaneous, dilatation-tracheotomy. After a period of 2 months, in an emergency situation of an acute inspiratory (and expiratory) stridor, the ensuring of airways was performed. The reopening of the previous dilatation tracheotomy with intubation by a child tracheotomy-tube No. 4 was immediately completed by emergency personnel. After immediate readmission to our hospital, the posttracheostomy (postintubation) long multisegmental tracheal stenosis was diagnosed in this case (Figure 1).

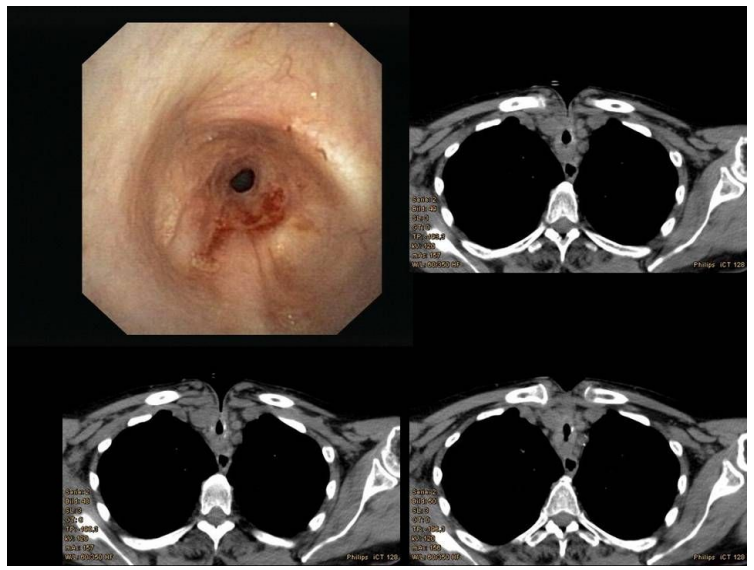

Figure 1. Images of posttracheotomy and postintubation long tracheal stenosis. The endoscopic view of the subglotic region shows the beginning of the stenosis, the CT scans of the deeper levels of the lesion-the tracheotomy can be easily recognized. 
For the stabilization of the tracheal wall and for ensuring the airways in this multimorbid patient, the permanent surgical tracheotomy (tracheofissure) (Figure 2) with mucocutaneous anastomosis together with the application of the Montgomery T-tube were performed (Figure 3).

After the significant clinical stabilization of the patient, the trachea was reconstructed by a segmental resection with end-to-end anastomosis. A segment of $8 \mathrm{~cm}$ of the trachea was resected.

The further postoperative course was uneventful and the patient was discharged 2 weeks after the procedure.

The tracheobronchoscopy showed a nicely healed anastomosis (Figure 4).

The patient has completely recovered, with a stable respiratory system performing her cardiac rehabilitation.

\subsection{Case 2}

The second patient is a young 39 year old female with an extreme obesity $(160 \mathrm{~kg})$ who had postintubation tracheal

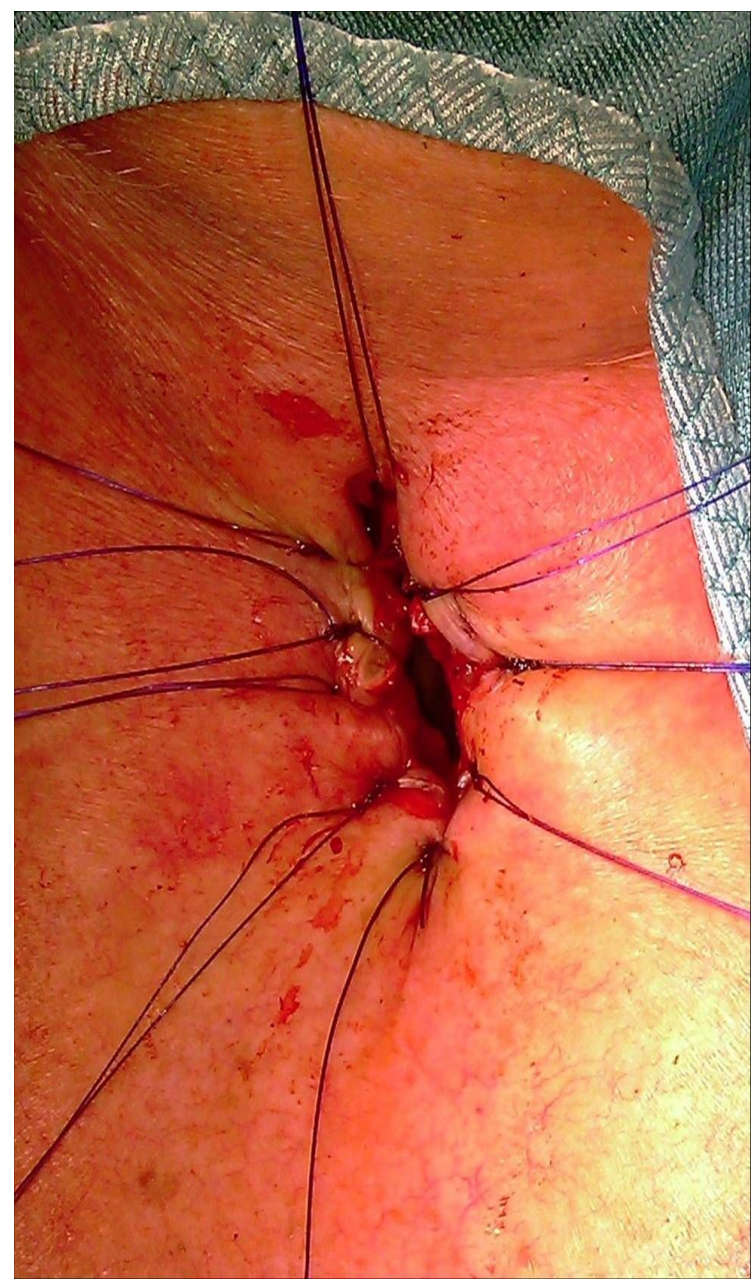

Figure 2. Permanent tracheotomy-tracheofissure is a precondition for the T-tube application.
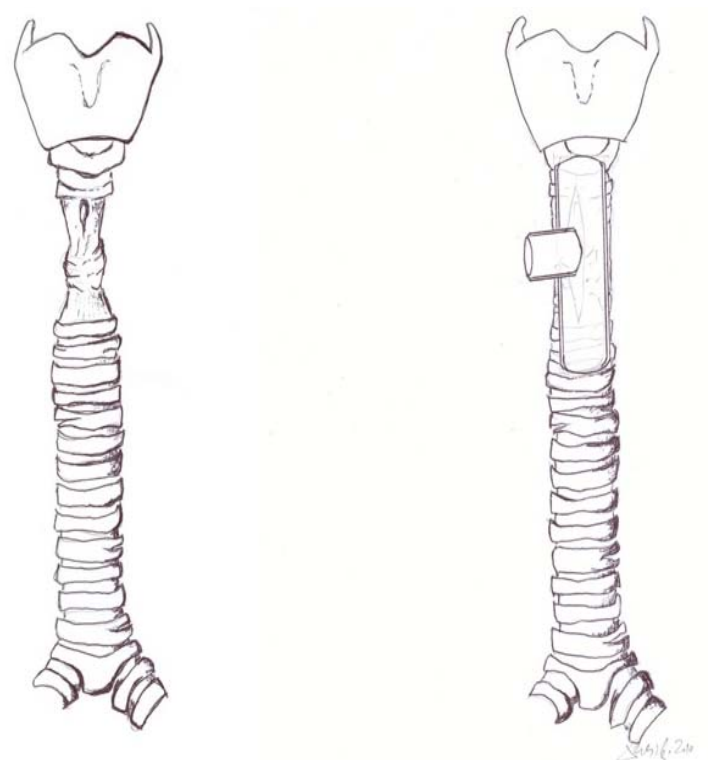

Figure 3. Multisegmental long tracheal stenosis (Scheme). For the stabilization of the tracheal wall and for ensuring the airways the Montgomery T-tube was placed into the tracheal stenosis.

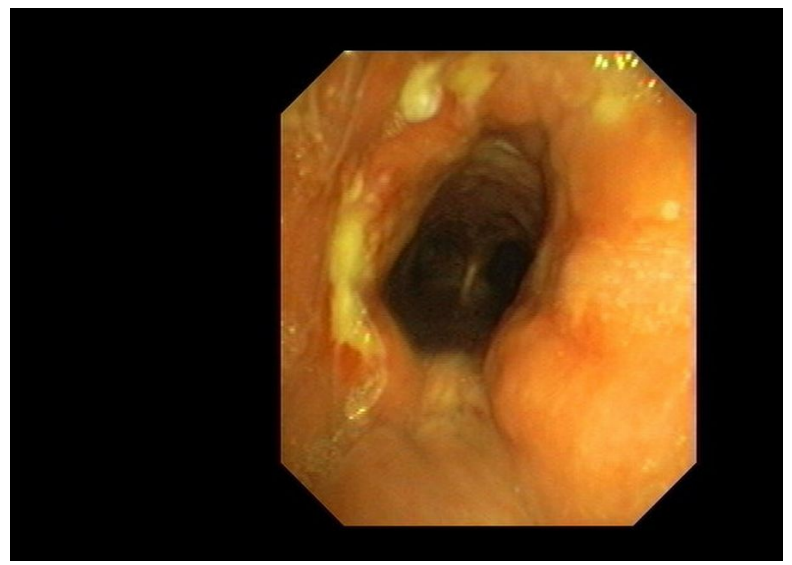

Figure 4. Endoscopic view of the tracheal anastomosis 2 weeks after the successful procedure.

stenosis after long-term intubation due to COPD. Similarly to the first patient, the acute tracheotomy/tracheofissure with T-tube stenting were initially performed. Within a period of 9 months, continuing the conditioning, the patient is currently waiting for the definitive reconstruction of the stenotic trachea.

In these two patients, the T-tube was used as a bridge to definitive reconstructive surgery. The following, last case presents a situation where the T-tube stenting was performed after the reconstruction tracheal surgery.

\subsection{Case 3}

In a 30-year-old female patient after a car accident, the T-tube was added to the procedure after the resection of 
the trachea in order to ensure the anastomosis. The Ttube was successfully removed 2 months later, the bronchoscopy showed a nicely healed anastomosis of the trachea. As was already stated above-in this case the stenting by T-tube was performed after the segmental resection as an adjunct to primary tracheal reconstructtion.

\section{Discussion}

\subsection{Surgical Technique}

The surgical technique for segmental tracheal resection with end-to-end anastomosis is well-known and has already been described and introduced elsewhere [8,9].

Here, only a brief description of its most important steps is given:

- Surgical approach should provide the best exposure of the trachea, and its chosen type depends on the level of the stenotic lesion; for the proximal lesion, the cervical incision is preferred, for the middle and the distal part of trachea, the median sternotomy and the posterolateral thoracotomy are the recommended approaches.

- Sufficient preparation and mobilization of the whole trachea is mandatory to achieve a tension-free anastomosis after the resection of the stenotic segment.

- The dissection of the trachea has to be done close to the trachea to avoid damage to the recurrent nerve, especially near the cricoid.

- The stenotic segment of the trachea should be completely removed; the future anastomosis should be constructed in healthy, vital tissue without granulations or scars.

- The recommended technique of tracheal anastomosis is an interrupted single-layer suture by monofila- ment, absorbable material of 3-0 or 4-0 being tied out.

- The tracheal anastomosis can be covered (wrapped) by some autologous pedicled flap e.g. intercostal muscle flap, pedicled pericardial flap, etc.

- Early extubation of the patient with spontaneous breathing and coughing activities postoperatively are also important.

- Stenting can be added to procedure in case of problematic anastomosis in complex tracheal injuries in order to ensure the reconstruction $[10,11]$.

In our first two cases, the temporary stenting by a Montgomery T-tube before the surgery was performed. This is necessary to achieve a stable (not collapsed) tracheal wall in its initially long, multisegmental stenotic stage. The relatively long T-tube stent with its horizontal branch offers a unique service it can serve as a temporary tracheostomic tube with stenting the airway also above the tracheostomy. The brief introduction of the T-tube follows in the next section.

\subsection{Stenting by T-Tube}

In 1964, Dr. Wiliam W. Montgomery used, for the first time, a two piece rigid acrylic stent during the reconstruction surgery of the cervical trachea to prevent postoperative tracheal stenosis [12]. This stent was designed as a combination tracheal stent and tracheotomy tube, but it proved to be too rigid, with significant complexity in manufacturing and insertion. Nonetheless, it served as a prototype for the Montgomery T-tube tracheal stent that was introduced by Montgomery in 1965 [13]. The improved version was a one-piece flexible silicone stent that possessed greater flexibility and caused minimal tissue reaction [14]. Its greatest advantage is that this T-tube serves as an internal stent as well as a tracheostomic tube. Its smooth and non-immersed surface restricts mucous sputum adherence and incrustation creation.

It has to be said that the silicone gum material is so far the best material for temporary tracheal stenting. It is rigid enough to restrict the narrowing of tracheal lumen during the granulation tissue maturation and, on the other hand, it is fine (smooth) enough to allow tracheal epithelium growth through granulations $[11,15]$. The therapy of stenting is time-consuming. The period of time necessary for trachea wall stabilization and trachea mucosa healing individually differs, which is why the patients retained the T-tubes for different time periods. They are well tolerated by patients and, compared to conventional tracheotomy tubes, they have several advantages. They preserve normal respiration and phonation, minimal cough and tissue reaction due to the (already mentioned) silicone material.

\subsection{Indications for T-Tube Applications}

In general, the T-tube can be applied in all cases of tracheal stenosis, where its radical segmental resection is not feasible or performable. These are the three situations wherein the T-tube can be inserted, as:

a temporary stent before segmental resection

a temporary stent after segmental resection

a single intervention-generally in all patients with long and multi-segment stenoses, and also in those with severe comorbidity, where the radical segmental resection is not feasible.

For the standard indication criteria, see Table $\mathbf{1 .}$

To complete this section, it has to be mentioned that, in general, tracheal stenosis can be managed in three different ways, incl. segmental tracheal resection, endoscopic stenting, recanalization via direct techniques (stenotic segment dilatation with discision/excision of stenotic granulated tissue surgically, or by laser evaporation).

The management of a tracheal stenotic lesion always requires an individual approach considering not only 
Table 1. Standard indication criteria for T-tube application.

\begin{tabular}{|c|c|c|}
\hline $\begin{array}{l}\text { Before segmental resection as a temporary } \\
\text { stent }\end{array}$ & After segmental resection & As a single intervention \\
\hline $\begin{array}{l}\text { complicated } \\
\text { tracheal lesion }\end{array}$ & $\begin{array}{l}\text { considering a non-reliable suture } \\
\text { (inflammation, tension) as a preven- } \\
\text { tion of restenosis }\end{array}$ & non-resectable tumors \\
\hline $\begin{array}{l}\text { Significant } \\
\text { inflammatory changes on trachea }\end{array}$ & $\begin{array}{l}\text { anastomosis insufficiency, margins' } \\
\text { separation, restenosis }\end{array}$ & long stenotic segments (over 50\%) \\
\hline tracheo-esophageal fistula & $\begin{array}{l}\text { obstructions in the area of the vocal } \\
\text { cords }\end{array}$ & multi-segmental stenoses \\
\hline non-compliant patient & & $\begin{array}{c}\text { accompanying problems, which contra-indicate segmental } \\
\text { resection (fibrosis, inflammation in the surrounding area, } \\
\text { situation after repeated interventions) }\end{array}$ \\
\hline
\end{tabular}

the local (tracheal wall) but also the general-condition of the suffering individual.

\subsection{Follow-Up, Management of T-Tube Bearers}

During the regular check-ups of T-tube patients, besides for other activities, biopsies were also removed from the tracheal mucous membrane and the reaction of mucosa was studied. During the stenting procedure by any type of endoprosthesis there was no evidence of the creation of a full-valued, original respiration epithelium. Only metaplastic changes of the mucous layer could always be seen, regardless of which type of endoprosthesis was used. This metaplasis was created by squamous cells with their hyperplasy, but without dysplasia. On the surface layers, parakeratosis was found; the top layers were usually covered by a film that contained polymorphonuclears. Lamina propria layers are always infiltrated by chronic inflammatory infiltrate. These changes can be always observed, but they were mostly found after trachea stenting by metallic endoprosthesis.

In all kinds of trachea reconstruction, a relatively good toleration of silicone material was observed. The Silicone T-tube causes minimal complications. Obstructions of the T-tube by dense sputum, which required T-tube removal and its replacing by a double-coated tracheotomy tube, were the most common complication. The location where most complications occurred was the upper part of the T-tube, in the place from where it was inserted to the subglottic area. Here, irritations and granulations could be sporadically observed. It is really difficult to estimate the correct length of the upper end of the T-tube's vertical branch. For this reason, it was necessary to perform endoscopic checks with the adjustment of the tube's upper end (due to the close position of vocal cords, and due to a necessity of granulations' overbridging). After inserting the T-tube's upper vertical part through the vocal cords and its long-term positioning in this area, no significant changes of the vocal cords were observed. After the removal of the tube, the patient's voice spontaneously appeared, even though it was not always clear.

\section{Conclusions}

From all of the above mentioned, it is clear that in the management of long multisegmental tracheal stenosis the surgical reconstruction together with temporary stenting by Montgomery T-tube play a significant role. A brief description of the most important steps within this management is given here. The period of time necessary for trachea wall stabilization and trachea mucosa healing differs individually and, therefore, the regular endoscopic check-ups and regular removal (with cleaning and replacing) of a T-tube is recommended, as an obstruction of the endoprosthesis by dense sputum is the most common complication.

After the significant stabilization of the tracheal wall and conditioning of the patient, the surgical reconstruction of the trachea is the final step of this management. The surgical approach should provide the best exposure of the trachea and its chosen type depends on the level of the stenotic lesion. In our study, the cervical approach without the necessity of sternotomy was performed in all patients. The next important recommendation is a sufficient preparation and mobilization of the whole trachea in order to achieve a tension-free anastomosis after the resection of the stenotic segment. The so-called mediastinal release (without any other mobilization maneuvers, e.g. suprahyoid laryngeal release) was the preferred mobilization technique in all of our patients.

To conclude, tracheal stenosis is a serious disease with increasing tendency. Among this increased number of tracheal stenosis, complicated, multi-segmental, long 
stenoses can be found rather often. There is also a growing number of patients with non-resectable tumors and patients after segmental tracheal resection, where anastomosis insufficiency developed. In such cases of dramatic situations, the optimal solution is to use a complex method with T-tube stenting together with surgery after the significant stabilization of the patient.

\section{Acknowledgements}

The author has no conflict of Interest.

\section{REFERENCES}

[1] H. C. Grillo, D. M. Donahue, D. J. Mathisen, J. C. Wain and C. D. Wright, "Postintubation Tracheal Stenosis. Treatment and Results," The Journal of Thoracic and Cardiovascular Surgery, Vol. 109, No. 3, 1995, pp. 486492.

[2] R. Nandakumar, C. Jagdish, C. B. Prathibha, C. Shilpa, V. Sreenivas, A. M. Balasubramanya and R. C. Nayar, "Tracheal Resection with End-to-End Anastomosis for Post-Intubation Cervical Tracheal Stenosis: Study of 14 Cases,” The Journal of Laryngology \& Otology, Vol. 125, No. 9, 2011, pp. 958-961. doi:10.1017/S002221511100137X

[3] H. C. Grillo, "Surgical Treatment of Postintubation Tracheal Injuries," The Journal of Thoracic and Cardiovascular Surgery, Vol. 78, No. 6, 1979, pp. 860-875.

[4] G. Massard, C. Rougé, A. Dabbagh, R. Kessler, J.-G. Hentz, N. Roeslin, J.-M. Wihlm and G. Morand, "Tracheobronchial Lacerations after Intubation and Tracheostomy," The Annals of Thoracic Surgery, Vol. 61, No. 5, 1996, pp. 1483-1487. doi:10.1016/0003-4975(96)00083-5

[5] J. Jougon, M. Ballester, E. Choukroun, J. Dubrez, G. Reboul and J. F. Velly, "Conservative Treatment for Postintubation Tracheobronchial Rupture,” The Annals of Thoracic Surgery, Vol. 69, No. 1, 2000, pp. 216-220.

[6] A. E. Melkane, N. E. Matar, A. C. Haddad, N. N. Nassar, H. G. Almoutran, Z. Rohayem, M. Daher, G. Chalouhy and G. Dabar, "Management of Postintubation Tracheal Stenosis: Appropriate Indications Make Outcome Differences,” Respiration, Vol. 79, No. 5, 2010, pp. 395-401.

\section{doi:10.1159/000279225}

[7] J. P. Jacobs, J. A. Quintessenza, L. M. Botero, H. M. van Gelder, J. M. Giroud, M. J. Elliott and C. Herberhold, "The Role of Airway Stents in the Management of Paediatric Tracheal, Carinal and Bronchial Disease,” European Journal of Cardio-Thoracic Surgery, Vol. 18, No. 5, 2000, pp. 505-512. doi:10.1016/S1010-7940(00)00534-0

[8] H. C. Grillo, "Circumferential Resection and Reconstruction of the Mediastinal and Cervical Trachea," Annals of Surgery, Vol. 162, No. 3, 1965, pp. 374-388. doi:10.1097/00000658-196509000-00007

[9] F. G. Pearson, J. D. Cooper, J. M. Nelems and A. W. P. Van Nostrand, "Primary Tracheal Anastomosis after Resection of the Cricoid Cartilage with Preservation of Recurrent Laryngeal Nerves," The Journal of Thoracic and Cardiovascular Surgery, Vol. 70, No. 5, 1975, pp. 806817.

[10] J. D. Cooper, T. R. Todd, R. Ilves and F. G. Pearson, "Use of the Silicone Tracheal T-Tube for the Management of Complex Trachea Injuries," The Journal of Thoracic and Cardiovascular Surgery, Vol. 82, No. 4, 1981, pp. 559-568.

[11] H.-C. Liu, K.-S. Lee, C.-J. Huang, C.-R. Cheng, W.-H. Hsu and M.-H. Huang, "Silicone T-Tube for Complex Laryngotracheal Problems," European Journal of Cardio-Thoracic Surgery, Vol. 21, No. 2, 2002, pp. 326-330. doi:10.1016/S1010-7940(01)01098-3

[12] W. W. Montgomery, "Reconstruction of the Cervical Trachea," Annals of Otology, Rhinology \& Laryngology, Vol. 73, No. 3, 1964, pp. 5-51.

[13] W. W. Montgomery, “T-Tube Tracheal Stent," Archives of Otolaryngology—Head \& Neck Surgery, Vol. 82, No. 3, 1965, pp. 320-321. doi:10.1001/archotol.1965.00760010322023

[14] M. M. Wahidi and A. Ernst, "The Montgomery T-Tube Tracheal Stent," Clinics in Chest Medicine, Vol. 24, No. 3, 2003, pp. 437-443. doi:10.1016/S0272-5231(03)00042-X

[15] W. E. Neville, P. J. Bolanowski and G. G. Kotia, "Clinical Experience with the Silicone Tracheal Prosthesis," The Journal of Thoracic and Cardiovascular Surgery, Vol. 99, No. 4, 1990, pp. 604-613. 